\title{
Catalytic Pyrolysis of Wild Reed over a Zeolite-Based Waste Catalyst
}

\author{
Myung Lang Yoo ${ }^{1}$, Yong Ho Park ${ }^{1}$, Young-Kwon Park ${ }^{2}$ and Sung Hoon Park ${ }^{1, *}$ \\ 1 Department of Environmental Engineering, Sunchon National University, 255 Jungang-ro, Suncheon, \\ Jeonnam 57922, Korea; yml1052@naver.com (M.L.Y.); mik900804@naver.com (Y.H.P.) \\ 2 School of Environmental Engineering, University of Seoul, Seoul 02504, Korea; catalica@uos.ac.kr \\ * Correspondence: shpark@sunchon.ac.kr; Tel.: +82-61-750-3816; Fax: +82-61-750-3810 \\ Academic Editors: Jang-Ho Lee and Animesh Dutta \\ Received: 30 December 2015; Accepted: 8 March 2016; Published: 15 March 2016
}

\begin{abstract}
Fast catalytic pyrolysis of wild reed was carried out at $500^{\circ} \mathrm{C}$. Waste fluidized catalytic cracking (FCC) catalyst disposed from a petroleum refinery process was activated through acetone-washing and calcination and used as catalyst for pyrolysis. In order to evaluate the catalytic activity of waste FCC catalyst, commercial $\mathrm{HY}$ zeolite catalyst with a $\mathrm{SiO}_{2} / \mathrm{Al}_{2} \mathrm{O}_{3}$ ratio of 5.1 was also used. The bio-oil produced from pyrolysis was analyzed using gas chromatography/mass spectrometry (GC/MS). When the biomass-to-catalyst ratio was 1:1, the production of phenolics and aromatics was promoted considerably by catalysis, whereas the content of oxygenates was affected little. Significant conversion of oxygenates to furans and aromatics was observed when the biomass-to-catalyst ratio of 1:10 was used. Activated waste FCC catalyst showed comparable catalytic activity for biomass pyrolysis to HY in terms of the promotion of valuable chemicals, such as furans, phenolics and aromatics. The results of this study imply that waste FCC catalyst can be an important economical resource for producing high-value-added chemicals from biomass.
\end{abstract}

Keywords: waste fluidized catalytic cracking (FCC) catalyst; fast pyrolysis; bio-oil; wild reed

\section{Introduction}

As rapid development and population increase have caused global environmental problems and depletion of fossil fuels, extensive efforts are devoted to renewable energy technologies to develop alternative energy resources and counteract global warming. Biomass has several strengths as an energy resource. Firstly, the net carbon emission from biomass is, at least theoretically, zero, i.e., it is carbon-neutral, because the carbon included in biomass originated from atmospheric $\mathrm{CO}_{2}$ as a result of photosynthesis of plants. Secondly, its sulfur content is very low compared to fossil fuels and hence it causes less air pollution upon combustion. Thirdly, it is renewable resource in that it is produced using solar energy. Due to these strengths, biomass is regarded as one of the most important future energy resources and the technologies for energy production from biomass have received large attention from all over the world [1,2].

Being a potential energy-producing biomass, reed is a C3 perennial grass with rich contents of lignin and cellulose. Wild reed that grows at Suncheon Bay Ecological Park (SBEP) is cut regularly to maintain the ecological equilibrium. Although some cut reed is recycled as construction materials, most of it is incinerated or landfilled. Therefore, finding an energy production method using SBEP wild reed is important in terms of both waste reduction and developing a new regional renewable energy resource.

Pyrolysis is a process in which organic matter is thermally converted to solid, liquid and gas products under a high-temperature oxygen-free atmosphere [3]. In particular, fast pyrolysis was 
devised to maximize the liquid pyrolysis product, called bio-oil. In order to obtain high bio-oil yield from pyrolysis, short gas residence time in reactor and high temperature rise rate are required [1].

Catalytic pyrolysis of biomass over acidic catalysts has attracted significant attention as a method of promoting the production of aliphatic and aromatic hydrocarbons [4,5]. Zeolite is an aluminosilicate material containing micropores. Having acid sites in its pores, zeolite is widely used in catalytic pyrolysis of biomass [6,7]. In a couple of previous studies, we reported the results of non-catalytic and catalytic fast pyrolysis of SBEP wild reed $[8,9]$. HZSM-5 zeolite catalysts were used for catalytic pyrolysis. Compared to non-catalytic pyrolysis, catalytic pyrolysis reduced the quantity of oxygenates in bio-oil considerably, while increasing the contents of furans and aromatics. This was attributed to the conversion of oxygenates to furans and aromatics on the Brønsted acid sites. A shortcoming of catalytic pyrolysis is the high price of the catalysts. Application of waste catalyst can reduce the cost of catalytic pyrolysis.

Fluidized catalytic cracking (FCC) catalyst, which is used in petrochemical refinery processes to reduce the molecular mass of oil species, is composed mostly of synthetic silica-alumina, containing $5-20 \mathrm{wt} \%$ of zeolite. In order to increase the hydrothermal stability of the catalyst, ultrastable Y (USY) zeolite, in which alkali metal ions of zeolite are ion-exchanged with $\mathrm{H}^{+}$or rare-earth metal cations, is usually used as the framework of FCC catalysts [10]. After use, the waste FCC catalyst consisting mostly of $\mathrm{Si}$ and $\mathrm{Al}$ is usually used as raw material for cement production with low value-added.

In a previous study [11], waste FCC catalyst was applied for the pyrolysis of polypropylene. The main species of the bio-oil obtained were found to be hydrocarbons in diesel range. Jang, et al. [12] activated waste FCC catalyst using $\mathrm{HCl}$ and $\mathrm{NaOH}$ solutions and used it for liquid-phase decomposition reaction of waste agricultural film. They reported that waste FCC catalyst can be an economical resource for recycling waste agricultural film although its catalytic activity was lower than commercial USY zeolite catalyst. These previous studies demonstrated the potential of waste FCC catalyst as a catalyst for biomass pyrolysis. To the best of our knowledge, however, the application of waste FCC catalyst for the pyrolysis of natural biomass has never been reported.

In this study, waste FCC catalyst was applied for the catalytic pyrolysis of wild reed. A zeolite catalyst HY was also used for comparison.

\section{Experimental}

\subsection{Materials}

Zeolite-based waste FCC catalyst and commercial HY zeolite catalyst were used in this study. $\mathrm{HY}$ with a $\mathrm{SiO}_{2} / \mathrm{Al}_{2} \mathrm{O}_{3}$ ratio of 5.1 was purchased from Zeolyst International. Waste FCC catalyst disposed from a petrochemical refinery process was soaked in acetone with a mass ratio of 1:10 and the mixture was stirred for $24 \mathrm{~h}$, aimed at washing out residual organic materials (physical activation). After the acetone washing, it was dried for an hour in a $60^{\circ} \mathrm{C}$ dryer. As another method of activation of waste FCC catalyst, the dried catalyst was calcined for $3 \mathrm{~h}$ in air using a $550{ }^{\circ} \mathrm{C}$ quartz tube reactor (chemical activation). All catalysts were pelletized into uniform size $(1.5-2.5 \mathrm{~mm})$ prior to use.

Thermo-gravimetric analysis (TGA) was performed using a pyris1 thermo-gravimetric analyzer (Perkin Elmer, Waltham, MA, USA) to evaluate the effects of physical and chemical activation treatments. During the analysis, temperature was increased at a rate of $30^{\circ} \mathrm{C} / \mathrm{min}$ from $30^{\circ} \mathrm{C}$ to $700{ }^{\circ} \mathrm{C}$. The specific surface area of catalysts was measured using Brunauer-Emmett-Teller (BET) method. After pre-treating catalyst samples in vacuum at $200{ }^{\circ} \mathrm{C}$, the adsorption and desorption of nitrogen by the samples were measured at $77 \mathrm{~K}$ using a BELSORP-MINI system (BEL Japan Inc., Osaka, Japan) to create the sorption isotherms. The specific surface area was determined from the isotherms based on the BET method. The crystalline structure of the catalysts was examined using a high-power X-ray diffractometer (XRD).

Wild reed of SBEP was collected for the experiments of this study. Dried wild reed sample was pulverized and sieved into uniform diameter of $2 \mathrm{~mm}$ on average $(1-3 \mathrm{~mm}$ ). The sample particles were then dried in an oven at $105 \pm 5^{\circ} \mathrm{C}$ for $24 \mathrm{~h}$. 


\subsection{Experiment and Analysis}

The batch-type reactor used in the previous studies $[8,9]$ was used for catalytic pyrolysis in this study. The reactor was a U-tube quartz reactor, with an internal volume of $50 \mathrm{~mL}$. The furnace temperature was controlled using a proportional-integral-derivative controller with an uncertainty of $\pm 5^{\circ} \mathrm{C}$. The reactor temperature was increased to the pyrolysis temperature instantly by inserting the reactor into pre-heated furnace.

The reactor was filled with a mixture of $1 \mathrm{~g}$ of reed sample and 1 or $10 \mathrm{~g}$ of catalyst. Pyrolysis was allowed to proceed at $500^{\circ} \mathrm{C}$ with a nitrogen gas flowrate of $50 \mathrm{~mL} / \mathrm{min}$ controlled at room temperature. Taking the volume expansion of carrier gas at $500{ }^{\circ} \mathrm{C}$ and the reactor volume reduction due to biomass and catalyst into account, the residence time in the reactor was $20 \mathrm{~s}$ and $14 \mathrm{~s}$ with the catalyst mass of $1 \mathrm{~g}$ and $10 \mathrm{~g}$, respectively. The reactor was purged with nitrogen gas for $5 \mathrm{~min}$ before the pyrolysis experiment to make the reactor atmosphere oxygen-free. All the experiments were conducted in triplicate to obtain the average and standard deviation of bio-oil yield.

The vapor-phase pyrolysis product was quenched using a condenser (RW1025G, JEIO TECH). The condensed liquid product (bio-oil) was analyzed using gas chromatography/mass spectrometry (GC/MS) (QP2010, Shimadzu, Japan) equipped with an HP-5 MS (30 m $\times 0.25 \mathrm{~mm} \times 0.25 \mu \mathrm{m})$ capillary column. Bio-oil was dissolved in HPLC-grade acetone with a 1:10 mass ratio prior to analysis. After being stabilized for $5 \mathrm{~min}$ at $40^{\circ} \mathrm{C}$, temperature was increased to $200^{\circ} \mathrm{C}$ at a rate of $5^{\circ} \mathrm{C} / \mathrm{min}$ and then to $300{ }^{\circ} \mathrm{C}$ at a rate of $20^{\circ} \mathrm{C} / \mathrm{min}$. Then $300^{\circ} \mathrm{C}$ was maintained for $10 \mathrm{~min}$. The peaks appearing in the mass spectra obtained were interpreted using the NIST05 library.

The gas product that was not condensed in the condenser was collected in a Teflon bag for $20 \mathrm{~min}$ and was analyzed later using gas chromatography (ACME 6000, Young Lin Instrument, Co., Ltd., Anyang, Korea) equipped with a thermal conductivity detector (TCD) and a flame ionization detector (FID). $\mathrm{CO}$ and $\mathrm{CO}_{2}$ were analyzed using TCD with a Carboxen $1000(15 \mathrm{ft} \times 1 / 8 \mathrm{in})$ column, whereas FID with HP-plot $\mathrm{Al}_{2} \mathrm{O}_{3} / \mathrm{KCl}(50 \mathrm{~m} \times 0.322 \mathrm{~mm} \times 8.0 \mu \mathrm{m})$ column was used for the analysis of $\mathrm{C}_{1}-\mathrm{C}_{10}$ hydrocarbons.

\section{Results and Discussion}

The TGA analysis results of the catalysts are shown in Figure 1. The weight reduction is explained by the decomposition of carbonaceous material deposited on the surface of the waste catalyst. The mass of non-treated waste FCC catalyst (FCC) and the acetone-treated waste FCC catalyst (FCC-acetone) kept decreasing until the end of the analysis. FCC-acetone showed an even higher mass reduction than non-treated FCC during the TGA analysis, indicating that the physical activation was not very effective in removing the carbon deposit and that it rather caused the adsorption of acetone, leading to an increase of organic residue on the catalyst surface. On the other hand, the mass of chemically activated waste FCC catalyst (FCC-calcined) stopped decreasing at $550{ }^{\circ} \mathrm{C}$, indicating that calcination was effective in removing organic deposit on the catalyst surface to a considerable extent. The derivative thermogravimetry (DTG) curves are shown in Figure 2. Although all the three curves showed similar trend, FCC-calcined showed the highest maximum mass reduction rate around $100^{\circ} \mathrm{C}$.

The BET surface area, pore size, and pore volume of the catalysts were summarized in Table 1. The specific surface area was increased significantly by both activation treatments but the effect of calcination was larger than that of acetone washing. Pore size and pore volume did not show large difference among the catalysts. Based on the TGA analysis and BET surface area measurement results, chemical activation was more effective in removing carbon deposit and organic residues on the catalyst surface. The XRD analysis showed that the waste FCC catalyst had the same basic structure as HY zeolite and that physical and chemical activations did not alter the crystalline structure of the catalyst. 


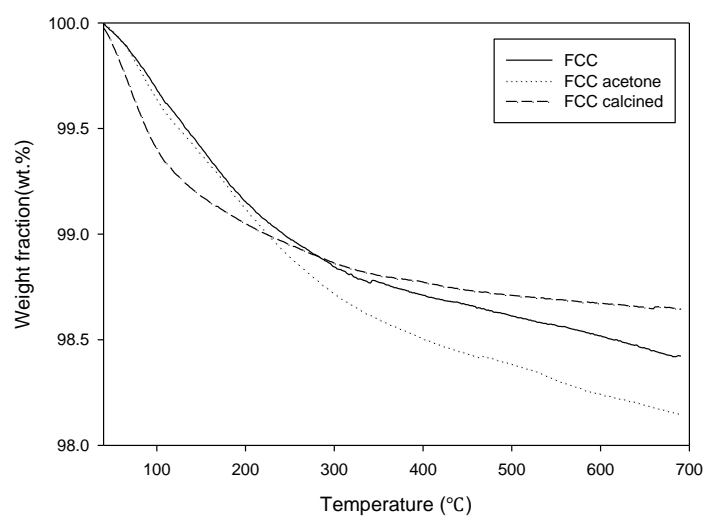

Figure 1. Thermo-gravimetric analysis (TGA) curves of catalysts.

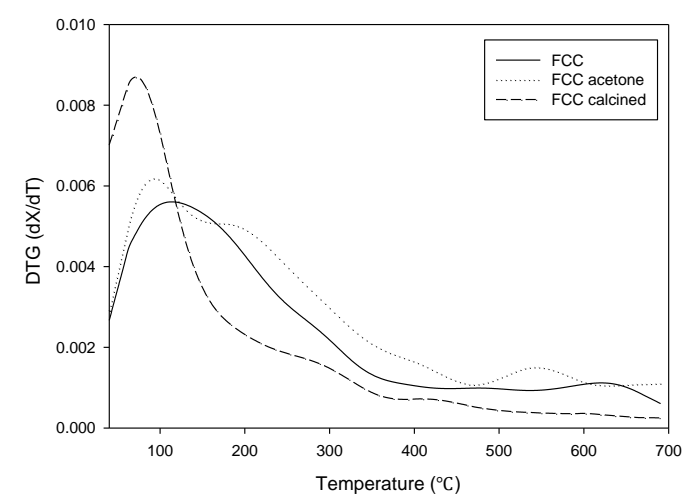

Figure 2. Derivative thermogravimetry (DTG) curves of catalysts.

Table 1. Brunauer-Emmett-Teller (BET) surface area, pore size and pore volume of the catalysts. Fluidized catalytic cracking: FCC.

\begin{tabular}{cccc}
\hline Catalysts & BET Surface Area $\left(\mathrm{m}^{2} / \mathbf{g}\right)$ & Pore Size $(\mathbf{n m})$ & Pore Volume $\left(\mathrm{cm}^{2} / \mathbf{g}\right)$ \\
\hline FCC & 136 & 6.67 & 0.1574 \\
FCC-acetone & 146 & 6.96 & 0.1402 \\
FCC-calcined & 159 & 6.65 & 0.1404 \\
\hline
\end{tabular}

Figure 3 shows the bio-oil yields obtained from the pyrolysis of reed conducted under different catalytic conditions. The error bar indicates the standard deviation obtained from the triplicate experiments. In the non-catalytic pyrolysis, the yields of oil, solid residue and gas were $50.7 \%, 22.0 \%$, and $27.3 \%$, respectively. Catalytic pyrolysis with a biomass-to-catalyst mass ratio of 1:1 led to a lower oil yield (and a higher gas yield) compared to non-catalytic pyrolysis mainly due to decomposition of oil species into gaseous species (with lower molecular mass). However, when the catalyst dosage was increased further (to a biomass-to-catalyst mass ratio of 1:10), the oil yield increased because the coke (solid residue) formation was suppressed by catalysts.

The GC-MS chromatogram of the bio-oil produced in this study showed more than 100 peaks. Therefore, all the bio-oil species detected in this study were grouped into seven categories: acids, oxygenates, phenolics, aliphatic hydrocarbons (aliphatics hereafter), monocyclic aromatic hydrocarbons (aromatics hereafter), polycyclic aromatic hydrocarbons (PAHs), and nitrogen-containing species ( $\mathrm{N}$ compounds hereafter). Figure 4 compares the bio-oil compositions (expressed in area \%) obtained using different catalysts: acetone-washed waste FCC catalyst (FCC-acetone), waste FCC catalyst calcined for $3 \mathrm{~h}$ after acetone-washing (FCC-calcined), and commercial HY. The results obtained with two different biomass-to-catalyst ratios 1:1 and 1:10 are shown separately. 


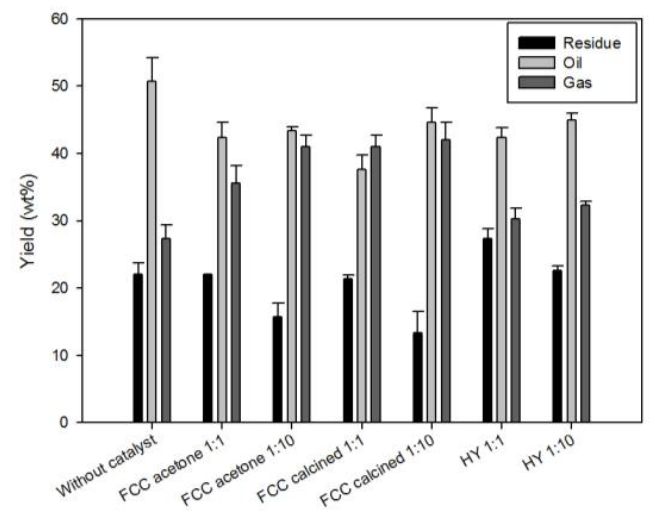

Figure 3. Yields of solid, liquid, and gas products of pyrolysis obtained under different catalytic conditions.

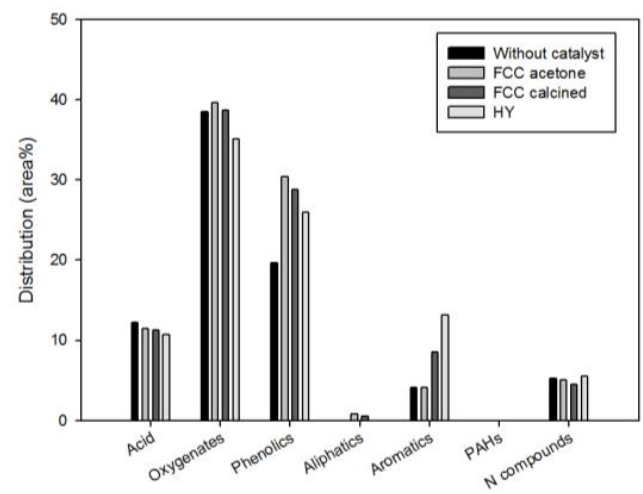

(a)

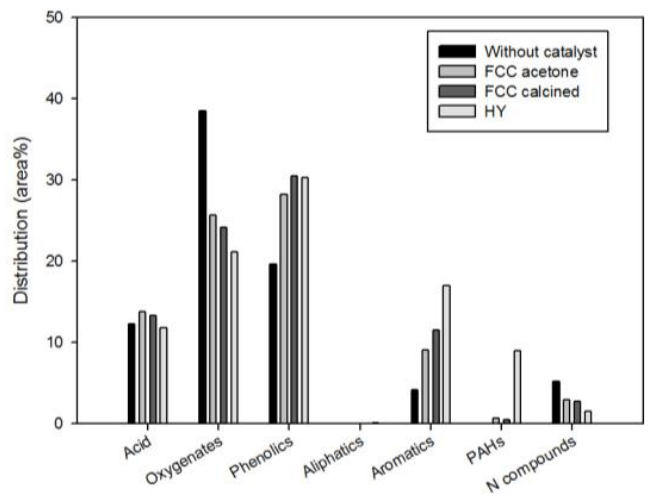

(b)

Figure 4. Pyrolysis product distribution obtained under different catalytic conditions at $500{ }^{\circ} \mathrm{C}$ : (a) biomass:catalyst $=1: 1$; and (b) biomass:catalyst $=1: 10$.

When the biomass-to-catalyst ratio was 1:1, phenolics (FCC-acetone, FCC-calcined, and HY) and aromatics (FCC-calcined and HY) were increased significantly by catalysis, while the contents of the other species were little affected by catalysis. When the biomass-to-catalyst ratio was 1:10, the content of oxygenates was reduced considerably, while the contents of phenolics and aromatics were increased significantly for all catalysts. The $\mathrm{N}$ compounds also decreased by all catalysts. Considerable increase in PAHs content was obtained only for HY. The conversion of oxygenates to aromatics over acid sites of zeolite-based catalysts is a well-known phenomenon; xylan, which is a thermally unstable fibrin linking cellulose and lignin, is easily decomposed on the acid sites and converted to aromatics through decarbonylation and aromatization $[13,14]$.

Acids were mostly acetic acid. The content of acids did not change significantly as a result of catalysis regardless of the catalyst dosage. Acetic acid contained in liquid fuels can cause corrosion of pipes and engines, while it can be used for producing bulk-chemical, vinegar, cleansing agent, vinyl acetate, acetic anhydride, esters, solvent, and road deicer (as calcium acetate) if it is separated properly [15]. Therefore, it must be separated from bio-oil before using the oil.

The main species among PAHs was naphthalene. Naphthalene is regarded as a high-value-added chemical because it can be widely used as a raw material for producing a number of chemical products, such as synthetic resin, pesticide and dye [7]. PAHs were not produced from non-catalytic pyrolysis and from catalytic pyrolysis with the biomass-to-catalyst ratio of 1:1. On the other hand, when the biomass-to-catalyst ratio was 1:10, significant quantity (9.01\%) of PAHs were detected for HY. The PAHs content obtained from waste FCC catalyst was marginal.

Figure 5 shows the detailed species distribution of oxygenates obtained under different catalytic conditions. While considerable quantity of levoglucosan (5.92\%) was produced from non-catalytic 
pyrolysis, pyrolysis with the biomass-to-catalyst ratio of 1:1 reduced it dramatically: 0.78\% (FCC-acetone), $0.75 \%$ (FCC-calcined), and 2.08\% (HY). Further, when the biomass-to-catalyst ratio was 1:10, virtually no levoglucosan remained. The conversion of levoglucosan on the acid sites of catalysts to furans and aromatics has been reported repeatedly in previous studies $[6,16,17]$.

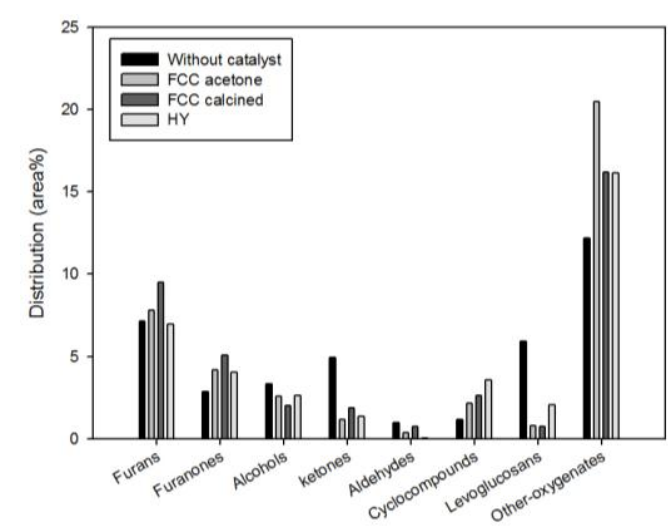

(a)

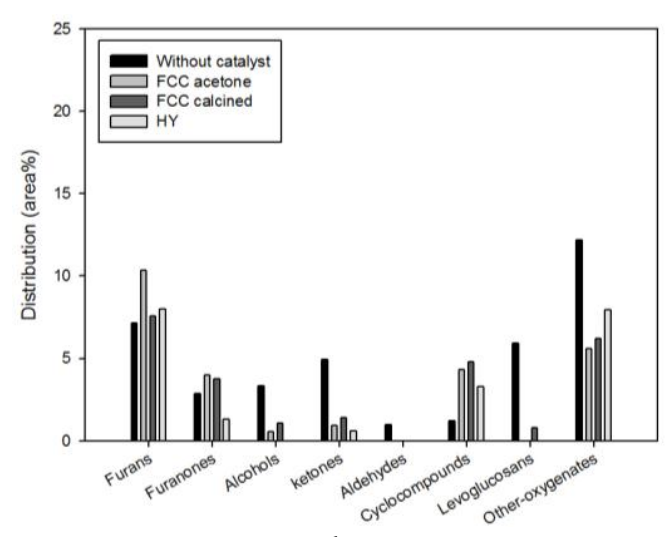

(b)

Figure 5. Detailed species distributions of oxygenates obtained from non-catalytic and catalytic pyrolyse of wild reed: (a) biomass:catalyst $=1: 1$; and $(\mathbf{b})$ biomass:catalyst $=1: 10$.

Furans are widely used in the petrochemical industry for producing furan resin, fuel additives, and medicines. Furans are known to be produced from the dehydration reaction of carbohydrate (e.g., levoglucosan) on the acid sites of catalysts [16]. The increase in furans content due to catalysis was smaller than the reduction in levoglucosan content (Figure 5). This was attributed to the conversion of levoglucosan to furanones and cyclocompounds due to dehydrogenation [17] and the production of aromatics due to aromatization reaction [16].

Phenolics are another high-value-added products of pyrolysis of biomass. They are produced from the decomposition of lignin contained in biomass. Figures 6 and 7 show the detailed species distribution of phenolics obtained from different catalytic conditions. In both figures, low-molecular-mass phenolics (a) and high-molecular-mass phenolics (b) are shown separately. Pyrolysis with the biomass-to-catalyst ratio of 1:1 (Figure 6) promoted the production of low-molecular-mass phenolics to a large extent, while high-molecular-mass phenolics were increased or decreased depending on the species. This result is attributed to promoted decomposition of lignin to phenolics and of high-molecular-mass phenolics to low-molecular-mass phenolics or aromatics owing to deoxygenation (dehydration, decarbonylation, and decarboxylation) and cracking occurring on the acid sites of the catalysts [7,18]. When the catalyst dosage was increased further (Figure 7), the conversion of high-molecular-mass phenolics to low-molecular-mass phenolics was more evident. All the high-molecular-mass phenolics except 2,6-dimethoxy-phenol, whose molecular mass is the smallest among them, were decreased by pyrolysis. In particular, 2-methoxy-4-(1-propenyl)-phenol and 2-methoxy-4-vinylphenol, which were removed or considerably decreased by pyrolysis with the biomass-to-catalyst ratio of 1:10, are unsaturated compounds containing $\mathrm{C}=\mathrm{C}$ bonds that are not inside benzene rings. Since they can cause the instability of fuels, the removal of these compounds is advantageous in terms of the oil quality improvement.

Figure 8 shows the most valuable four monocyclic aromatic compounds produced under different catalytic conditions: benzene, toluene, ethylbenzene, and xylene (often called BTEX). It is shown that most aromatics produced in this study were benzene; a little toluene and xylene were produced only by using HY with the biomass-to-catalyst ratio of 1:10. The production of aromatics was promoted by catalysis and the effect of catalysis was stronger when the catalyst dosage was higher. This result is in good agreement with the reports of previous studies that acid sites are required to produce aromatics during biomass pyrolysis $[4,5,7,9,16]$. BTEX are very important raw materials in the petrochemical 
industry. Therefore, the production of BTEX using waste biomass and waste catalyst achieved in this study has deep implications for developing resources that can replace fossil fuels.

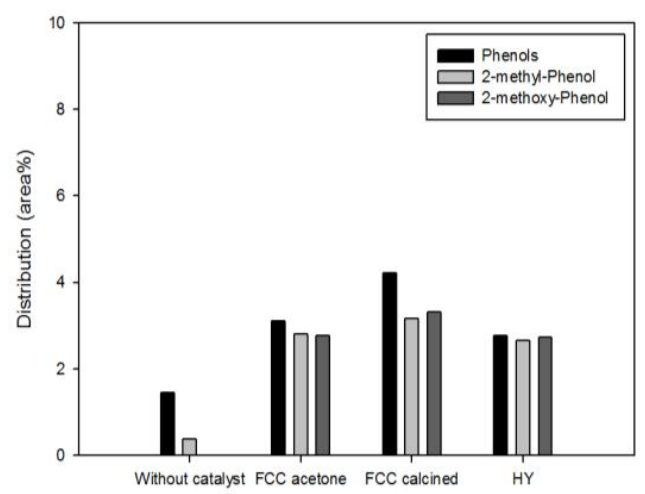

(a)

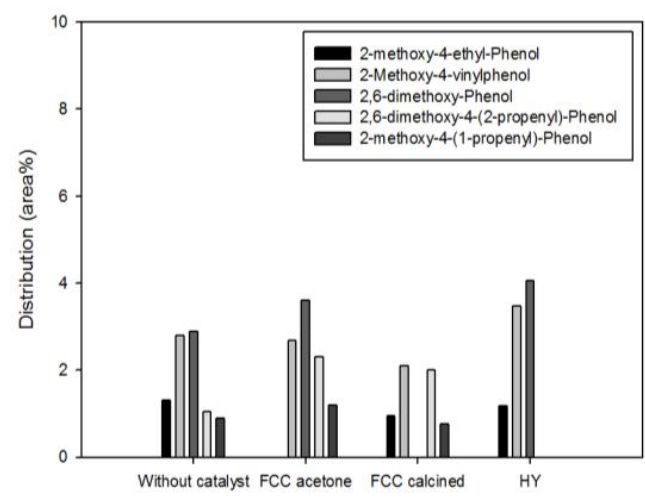

(b)

Figure 6. Detailed phenolic species distributions obtained from non-catalytic and catalytic pyrolyses with biomass:catalyst $=1: 1:$ (a) small-molecular-mass phenolics; and (b) large-molecular-mass phenolics.

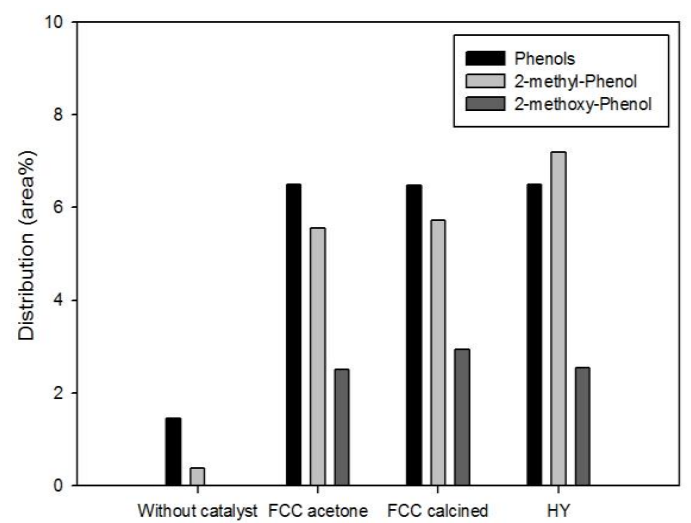

(a)

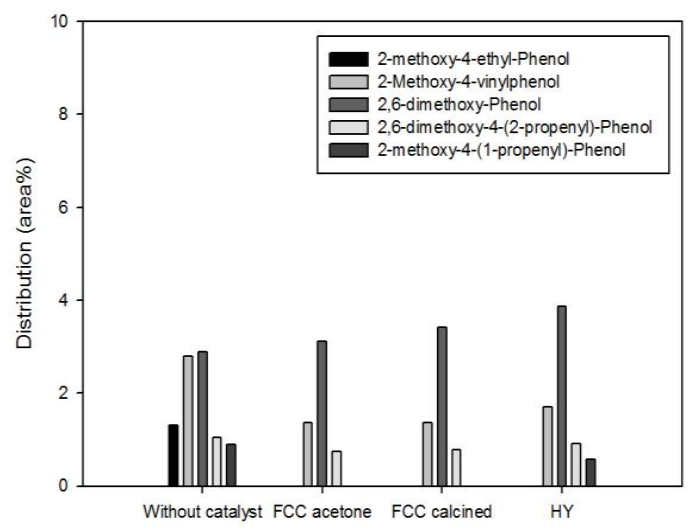

(b)

Figure 7. Detailed phenolic species distributions obtained from non-catalytic and catalytic pyrolyses with biomass:catalyst = 1:10: (a) small-molecular-mass phenolics; and (b) large-molecular-mass phenolics.

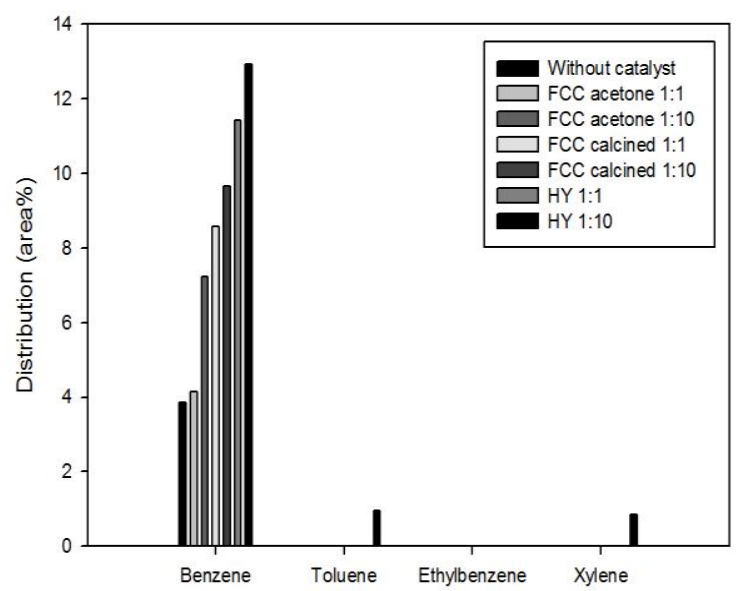

Figure 8. Comparison of the benzene, toluene, ethylbenzene, and xylene (BTEX) fractions obtained from non-catalytic and catalytic pyrolyses of wild reed. 
The gas products obtained over FCC-calcined with the biomass-to-catalyst ratio of 1:1 and 1:10 are shown in Figure 9. The results obtained without catalyst are shown together. Catalysis apparently increased the production of $\mathrm{C}_{1}-\mathrm{C}_{4}$ hydrocarbon, $\mathrm{CO}$, and $\mathrm{CO}_{2}$. $\mathrm{C}_{5}-\mathrm{C}_{6}$ components were not detected, indicating that the condenser worked properly. Enhanced production of $\mathrm{CO}$ and $\mathrm{CO}_{2}$ can be attributed to the catalytic deoxygenation (decarbonylation and decarboxylation) of oxygenates in bio-oil. Catalytic cracking of bio-oil components converted large-molecular-mass compounds into $\mathrm{C}_{1}-\mathrm{C}_{4}$ hydrocarbons. A high correlation between the enhanced $\mathrm{CO}$ production due to catalytically promoted decarbonylation and decarboxylation and increased production of aromatic hydrocarbons has been reported [19], which is in good agreement with the result of this study. Increase in the catalyst dosage (change of the biomass-to-catalyst ratio from 1:1 to 1:10) resulted in reduced $\mathrm{CO}_{2}$ production, while the production of $\mathrm{C}_{1}-\mathrm{C}_{4}$ hydrocarbons was enhanced. This can be attributed to enhanced catalytic demethylation and demethoxylation of lignin-derived phenolic compounds, resulting in reduced content of phenolics with methoxy functional groups in bio-oil [20].

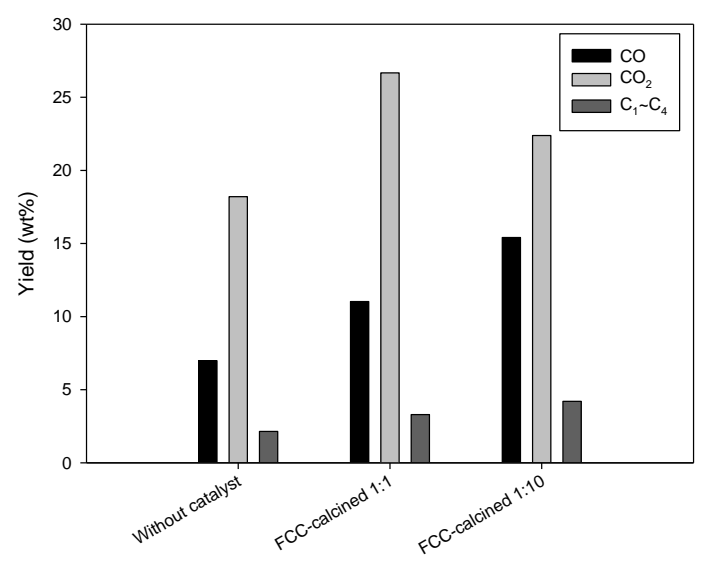

Figure 9. Detailed species distributions of gas obtained from non-catalytic and catalytic pyrolyses of wild reed.

\section{Conclusions}

Wild reed of SBEP was pyrolyzed over waste FCC catalyst and HY zeolite catalyst. Catalysis reduced the yield of bio-oil because of enhanced decomposition of oil species into gaseous species. However, the use of excess catalyst rather increased the bio-oil yield resulting from suppressed coke formation.

The production of phenolics and aromatics were promoted considerably by catalysis. Oxygenates were reduced significantly when catalyst dosage was very high. In particular, most levoglucosan was removed by catalysis, converting to other compounds such as furans and aromatics on the acid sites of the catalysts.

Waste FCC catalyst activated through acetone-washing and calcination for $3 \mathrm{~h}$ exhibited considerable catalytic activity which was comparable to that of $\mathrm{HY}$ zeolite catalyst. The results of this study imply that waste FCC catalyst can be an important economical resource to produce high-value-added chemicals from biomass.

Acknowledgments: This research was supported by Basic Science Research Program through the National Research Foundation of Korea (NRF) funded by the Ministry of Education, Science and Technology (grant number 2013R1A1A4A01005840).

Author Contributions: Young-Kwon Park and Sung Hoon Park conceived and designed the experiments; Myung Lang Yoo and Yong Ho Park performed the experiments; Myung Lang Yoo and Sung Hoon Park analyzed the data; Young-Kwon Park contributed reagents/materials/analysis tools; Myung Lang Yoo and Sung Hoon Park wrote the paper.

Conflicts of Interest: The authors declare no conflict of interest. 


\section{References}

1. Demirbas, A. Biomass resources for energy and chemical industry. Energy Educ. Sci. Technol. 2000, 5, 21-45.

2. Subramanian, P. A review on gasification of biomass. Renew. Sustain. Energy Rev. 2009, 13, 179-186.

3. Mohan, D. Pyrolysis of wood/biomass for bio-oil: A critical review. Energy Fuels 2006, 20, 848-889. [CrossRef]

4. Park, H.J.; Heo, H.S.; Jeon, J.K.; Kim, J.; Ryoo, R.; Jeong, K.E.; Park, Y.K. Highly valuable chemicals production from catalytic upgrading of radiata pine sawdust-derived pyrolytic vapors over mesoporous MFI zeolites. Appl. Catal. B Environ. 2010, 95, 365-373. [CrossRef]

5. Heo, H.S.; Kim, S.G.; Jeong, K.E.; Jeon, J.K.; Park, S.H.; Kim, J.M.; Kim, S.S.; Park, Y.K. Catalytic upgrading of oil fractions separated from food waste leachate. Bioresour. Technol. 2011, 102, 3952-3957. [CrossRef] [PubMed]

6. Choi, S.J.; Park, S.H.; Jeon, J.-K.; Lee, I.G.; Ryu, C.; Suh, D.J.; Park, Y.K. Catalytic conversion of particle board over microporous catalysts. Renew. Energy 2013, 54, 105-110. [CrossRef]

7. Kim, J.W.; Park, S.H.; Jung, J.; Jeon, J.K.; Ko, C.H.; Jeong, K.-E.; Park, Y.-K. Catalytic pyrolysis of mandarin residue from the mandarin juice processing industry. Bioresour. Technol. 2013, 136, 431-436. [CrossRef] [PubMed]

8. Park, Y.-K.; Yoo, M.L.; Heo, H.S.; Lee, H.W.; Park, S.H.; Jung, S.-C.; Park, S.-S.; Seo, S.-G. Wild reed of Suncheon Bay: Potential bio-energy source. Renew. Energy 2012, 42, 168-172. [CrossRef]

9. Park, Y.-K.; Yoo, M.L.; Jin, S.H.; Jung, S.-C.; Park, S.-S.; Park, S.H. Pyrolysis of Suncheon-Bay wild reed over zeolite catalysts. J. Renew. Sustain. Energy 2014, 6. [CrossRef]

10. Jeon, S.K.; Yang, J.G.; Kim, J.H.; Lee, S.S. Separation and Recovery of Ce, Nd and V from Spent FCC Catalyst. J. Korean Ind. Eng. Chem. 1997, 8, 679-684.

11. Bak, Y.C.; Choi, J.H.; Oh, S.H. The Effects of Zeolite-Type Catalysts on the Pyrolysis Reaction of PP to Produce Fuel-oil. J. Korea Chem. Eng. Res. 2012, 50, 442-448. [CrossRef]

12. Jang, N.P.; Park, J.W.; Seo, G. Liquid-Phase Degradation of Waste Agricultural Film over Used-FCC Catalysts. Korea Chem. Eng. Res. 2003, 41, 694-699.

13. Gutierrez, A.; Kaila, R.K.; Honkela, M.L.; Slioor, R.; Krause, A.O.I. Hydrodeoxygenation of guaiacol on noble metal catalysts. Catal. Today 2009, 147, 239-246. [CrossRef]

14. Sitthisa, S.; Resasco, D.E. Hydrodeoxygenation of Furfural over Supported Metal Catalysts: A Comparative Study of Cu, Pd and Ni. Catal. Lett. 2011, 141, 784-791. [CrossRef]

15. De Wild, P.; Reith, H.; Heeres, E. Biomass pyrolysis for chemicals. Biofuels 2011, 2, 185-208. [CrossRef]

16. Lee, I.G.; Jun, B.R.; Kang, H.K.; Park, S.H.; Jung, S.C.; Jeon, J.K.; Ko, C.H.; Park, Y.K. Catalytic Pyrolysis of Cellulose over SAPO-11 Using Py-GC/MS. Bull. Korean Chem. Soc. 2013, 34, 2399-2402. [CrossRef]

17. Shen, D.K.; Gu, S. The mechanism for thermal decomposition of cellulose and its main products. Bioresour. Technol. 2009, 100, 6496-6504. [CrossRef] [PubMed]

18. Carlson, R.T.; Tompsett, A.G.; Conner, C.W.; Huber, W.G. Aromatic Production from Catalytic Fast Pyrolysis of Biomass-Derived Feedstocks. Top. Catal. 2009, 52, 241-252. [CrossRef]

19. Wang, K.; Kim, K.H.; Brown, R.C. Catalytic pyrolysis of individual compounds of lignocellulosic biomass. Green Chem. 2014, 16, 727-735. [CrossRef]

20. Jin, S.H.; Lee, H.W.; Ryu, C.; Jeon, J.-K.; Park, Y.-K. Catalytic fast pyrolysis of Geodae-Uksae 1 over zeolites. Energy 2015, 81, 41-46. [CrossRef]

(C) 2016 by the authors; licensee MDPI, Basel, Switzerland. This article is an open access article distributed under the terms and conditions of the Creative Commons by Attribution (CC-BY) license (http:/ / creativecommons.org/licenses/by/4.0/). 